\title{
COMENTARIOS SOBRE LA NUEVA LEY DE INVERSIONES EXTRANJERAS DE VENEZUELA
}

\section{COMENTÁRIO À NOVA LEI DE INVESTIMENTOS DA VENEZUELA}

Ivette Esis Villarroel

Resumen: Junto a los convenios multilaterales y bilaterales en materia de promoción y protección de inversiones, coexisten legislaciones nacionales que buscan ofrecer al inversionista foráneo previsibilidad y seguridad jurídica en pro de atraer capital extranjero. Vista la reciente promulgación y publicación de la Ley venezolana, este trabajo pretende, por lado, examinar muy brevemente el régimen jurídico internacional de la inversión extranjera; $y$, por otro, analizar las principales novedades contenida en el nuevo instrumento legal.

Resumo: De maneira conjunta aos convênios multilaterais e bilaterais em matéria de promoção e proteção de investimentos, coexistem legislações nacionais que buscam oferecer ao investidor estrangeiro previsibilidade e segurança jurídica com o objetivo de atrair capital estrangeiro. Tendo em vista a recente promulgação e publicação da Lei venezuelana, este trabalho pretende, por um lado, examinar muito brevemente o regime jurídico internacional do investimento estrangeiro; e, por outro lado, analisar as principais novidades contidas no novo instrumento legal.

Palabras clave: Inversión extranjera, Ley de inversiones extranjeras, Venezuela, MERCOSUR

Palavras-chave: Investimento estrangeiro, Lei do investimento estrangeiro, Venezuela, MERCOSUL

\section{NOTAS INTRODUCTORIAS}

En fechas recientes, el Ejecutivo Nacional promulgó el Decreto No. 1.438 , de fecha 17 de noviembre de 2014, contentivo del Decreto Ley con

* Doctora en Derecho por la Universidad de Valencia, España. Magister Scientiarum en Derecho Internacional Privado y Comparado, Universidad Central de Venezuela. Abogada por la Universidad del Zulia. Profesora de Derecho Internacional Privado, Derecho Comparado y Medios Alternos de Resolución de Conflictos en la Universidad Metropolitana. Caracas Venezuela. E-mail: ivette.esis@gmail.com 
Rango, Valor y Fuerza de Ley de Inversiones Extranjeras (en lo adelante, Ley de Inversiones Extranjeras o LIE) ${ }^{1}$. Esta legislación se enmarca en el elenco de instrumentos legales promulgados por el Ejecutivo Nacional, con ocasión de la Ley Habilitante del año 2013, otorgada por el Poder Legislativo Nacional, con el propósito inicial de combatir la corrupción y defender la economía ${ }^{2}$.

Esta Ley, como veremos a continuación, deroga las disposiciones de la Ley de Promoción y Protección de Inversiones de 1999, promulgada por el Ejecutivo Nacional en el marco de la primera Ley Habilitante otorgada al entonces Presidente de la República ${ }^{3}$. La nueva legislación contempla una serie de disposiciones relativas a la calificación de inversión extranjera, el registro de dicha inversión ante autoridades competentes, el régimen de repatriación de capitales y el método de resolución de controversias, entre otros grandes aspectos.

A continuación, analizamos brevemente el contexto relativo al régimen jurídico internacional de las inversiones extranjeras y, de seguidas, las principales disposiciones de la legislación objeto de estudio de este trabajo.

\section{BREVE REFERENCIA AL RÉGIMEN JURÍDICO INTERNACIONAL DE LAS INVERSIONES EXTRANJERAS}

La circulación transfronteriza de capitales foráneos se ha convertido, hoy día, en parte muy esencial de nuestra realidad cotidiana. Los inversionistas extranjeros, en aras de obtener lucrativos rendimientos, buscan nuevos mercados para dinamizar sus actividades en otras regiones del mundo. Los Estados receptores de dicha inversión ante la necesidad de generar empleo, aumentar la productividad, impulsar la transferencia de tecnología y mejorar el contexto socio económico de su población, compiten entre sí para ofrecer las mejores condiciones económicas y legales para atraer dichos capitales ${ }^{4}$. Este juego de intereses genera un importantísimo volumen de inversión extranjera en el mercado transfronterizo.

De acuerdo a las reglas de Derecho Internacional, los Estados en ejercicio de su soberanía no están obligados, en principio, a admitir

\footnotetext{
1 Publicada en la Gaceta Oficial de la República Bolivariana de Venezuela No. 6.152 Ext., de fecha $18 / 11 / 2014$.

2 Ley que autoriza al Presidente de la República para dictar Decretos con Rango, Valor y Fuerza de Ley en las materias que se delegan, publicada en la Gaceta Oficial de la República Bolivariana de Venezuela No. 6.112 Ext., de fecha 19/11/2013.

3 Publicada en la Gaceta Oficial de la República Bolivariana de Venezuela No. 5.390 Ext., de fecha 22/10/1999.

4 ESIS VILLARROEL, Ivette "Inversión Extranjera: Oportunidades y Desafíos para los países receptores". En: VALENÇA FERRAZ, Carolina; SALOMÃO LEITE, Glauber; CECATO, Maria Áurea y NEWTON, Paulla da Costa (ed). Direito e Desenvolvimento Sustentável. São Paulo: Edit. Verbatim, 2013. p. 38.
} 
cualquier tipo de inversión extranjera en su territorio. Les asiste el Derecho a excluirla, a imponer restricciones y a dictar normas que la regulen. Ahora bien, una vez que la admiten para atender sus necesidades socioeconómicas, les asiste el deber de garantizar al inversionista foráneo un tratamiento mínimo de garantías de protección de su inversión ${ }^{5}$.

En la actualidad, la regulación relativa a la promoción y protección de inversiones extranjera se enmarca en un amplio entramado de (i) convenios multilaterales; (ii) acuerdos bilaterales; y, en menor proporción (iii) legislaciones nacionales. Veamos a continuación algunos ejemplos.

\subsection{Convenios Multilaterales y Bilaterales}

El lugar común de los instrumentos legales de carácter convencional consiste en aglutinar las reglas básicas que garanticen previsibilidad y seguridad jurídica tanto a los inversionistas como a los Estados receptores. Sin embargo, debemos también destacar que este sistema de fuentes $y$, en particular, las internacionales, es muy amplio y se caracteriza por tener un carácter profundamente fragmentado (bilateral o multilateral), lo que incide en sus distintos ámbitos de vigencia y aplicación material.

Según estadísticas publicadas por la UNCTAD, se calcula la existencia de, al menos 3200 acuerdos de promoción y protección de inversiones concluidos entre distintos países. De esa cantidad, existen 2924 acuerdos bilaterales ratificados ${ }^{6}$. En paralelo a esta enorme red de acuerdos, también coexisten otros convenios multilaterales tales como Tratado de Libre Comercio de América del Norte (TLCAN) ${ }^{7}$, la Asociación de Naciones del Sudeste Asiático (ASEAN) ${ }^{8}$, el Tratado de la Carta de Energía (TCE) ${ }^{9}$, el Tratado de Libre Comercio entre Estados Unidos, Centroamérica y República Dominicana (CAFTA-Dr) ${ }^{10}$, la Comunidad Andina de Naciones (CAN) ${ }^{11}$ y el Mercado Común del Sur $(\mathrm{MERCOSUR})^{12}$, en los que igualmente se establecen una serie de reglas de protección de inversiones en sus respectivos ámbitos de aplicación regional.

5 DOLZER, Rudolf y SCHREUER, Christoph. Principles of International Investment Law. New York: Oxford University Press, 2008. p. 7; FERNÁNDEZ MASIÁ, Enrique. Tribunales nacionales, arbitraje internacional y protección de las inversiones extranjeras. Madrid: Marcial Pons, 2008. p. 9; FERNÁNDEZ ROZAS, José Carlos. Tratado de Arbitraje Comercial en América Latina. Madrid: Iustel, 2008. p. 40.

6 UNCTAD. Towards a New Generation of International Investment Policies: UNCTAD's Fresh Approach to Multilateral Investment Policy-Making [en línea]. [consultado: 25/01/2015]. Disponible en: <http://unctad.org/en/PublicationsLibrary/webdiaepcb2013d6_en.pdf >.

7 Texto disponible en la página web: <http://www.naftanow.org> [consultado: 15/12/2014].

8 Texto disponible en: $<$ http://www.asean.org/> [consultado: 15/12/2014].

9 Texto disponible en: <http://www.encharter.org/> [consultado: 15/12/2014].

10 Texto disponible en: <http://www.caftaintelligencecenter.com $>$ [consultado: 15/12/2014].

11 Texto disponible en: <http://www.comunidadandina.org/> [consultado: 15/12/2014].

12 Texto disponible en: <www.mercosur.int > [consultado: 15/12/2014]. 
En el marco de MERCOSUR, constituido entre Argentina, Brasil, Paraguay, Uruguay y, más recientemente, Venezuela ${ }^{13}$, existen dos instrumentos importantes en materia de inversión foránea. Nos referimos a los Protocolos de Promoción y Protección de Inversiones de Colonia y Buenos Aires (para Estados partes y para Estados no partes, respectivamente $)^{14}$, cuyo objetivo consiste en propiciar la inversión en la Región a través de la implementación de normas claras y uniformes en materia de flujo de capitales y mecanismos de resolución de controversias $^{15}$.

Ambos instrumentos convencionales de carácter regional contienen una serie de garantías mínimas para los inversionistas foráneos en el mercado común, como el trato favorable, el principio de no discriminación, el trato justo y equitativo, la plena protección y seguridad, no expropiación salvo por razones de utilidad pública, el Derecho a las transferencias de capital hacia el país de origen del inversor, entre otras ${ }^{16}$. A pesar de su importancia y propósito, no están aún en vigencia por la falta de ratificación, en cada caso, de algunos o varios países miembros ${ }^{17}$.

\subsection{Legislaciones Nacionales}

Junto a los convenios multilaterales y bilaterales existentes en materia de promoción y protección de inversiones foráneas, varios Estados han promulgado leyes especiales en esta materia. Dichas legislaciones tienen como objetivo, en su mayoría, incrementar la captación de capital foráneo para la diversificación y el mejoramiento de las condiciones socioeconómicas existentes en cada país, a través del establecimiento de un marco jurídico previsible ${ }^{18}$. En el ámbito de

13 Ley Aprobatoria del Protocolo de Adhesión de la República Bolivariana de Venezuela al MERCOSUR y sus Anexos: "Tratado de Asunción", "Protocolo de Ouro Petro", "Protocolo de Olivos para la Solución de Controversias del MERCOSUR" y la "Lista de Productos paraguayos y uruguayos que, conforme al artículo 5 del Protocolo, gozarán de desgravación total e inmediata por parte de la República Bolivariana de Venezuela, publicada en la Gaceta Oficial de la República Bolivariana de Venezuela No. 38.482, de fecha 19/07/2006. La entrada efectiva de Venezuela al bloque se produjo años después.

14 Textos disponibles en: <http://www.mre.gov.py/v1/Adjuntos/mercosur/mercosurprincipal. htm> [consultado: 25/01/2015].

15 CASTILLO ARGAÑARÁS, Luís Fernando. "MERCOSUR e Inversiones Extranjeras. Una aproximación desde el Derecho Comparado y de la Integración". En: Âmbito Jurídico [en línea]. 2011, vol 14, n 84. Disponible en: <http://www.ambito-juridico.com.br/site?n_link_ argios_leitura\&revista_cderno $=19>$ [consultado el 25/01/2015].

16 FRİAS MILEO, María Lourdes. (2014), "Promoción y protección de la inversión en el MERCOSUR”. En: Un Siglo de Historia y Derecho. 100 años del Escritorio Tinoco, Travieso, Planchart \& Núñez (TTPßN). Caracas: TTP\&N y Universidad Católica Andrés Bello, 2014. p. $91-94$.

17 Veáse el estado de ratificaciones y vigencia de cada tratado en: <http://www.mre.gov.py/v1/ Adjuntos/mercosur/mercosurprincipal.htm $>$ y en <http://www.mercosur.int/t_generic.jsp?c ontentid=4827\&site $=1 \&$ channel $=$ secretaria $>$ [consultado: $25 / 01 / 2015$ ].

18 HERNÁNDEZ-BRETÓN, Eugenio. "Protección de inversiones en Venezuela". En: 
MERCOSUR, los países miembros contienen legislaciones en la materia. De ellas, analizamos las principales disposiciones de la novísima Ley de Inversiones de Venezuela.

\section{NOVEDADES DE LA LEY DE INVERSIONES EXTRANJERAS DE VENEZUELA}

De acuerdo a la Constitución de la República ${ }^{19}$, todas las personas naturales y jurídicas pueden dedicarse libremente a la actividad económica de su preferencia, sin más limitaciones que las previstas en el texto constitucional y la legislación local ${ }^{20}$. Asimismo, dispone que la inversión extranjera está sujeta a las mismas condiciones y requerimientos establecidos para la inversión nacional ${ }^{21}$.

La Ley de Inversiones Extranjeras, tal como mencionamos al comienzo de este Trabajo, derogó las previsiones de la Ley de Promoción y Protección de Inversiones de 1999 y su Reglamento. En términos generales, destacamos varias modificaciones contenidas en el nuevo instrumento legal:

(i) En primer lugar, suprime el artículo referido a la aplicación de la normativa de la Comunidad Andina de Naciones $(\mathrm{CAN})^{22} \mathrm{y}$, en particular, nos referimos a la Decisión 291 sobre el Régimen Común de Tratamiento a los Capitales Extranjeros y sobre Marcas, Patentes, Licencias y Regalías y a la Decisión 292 relativa al Régimen Uniforme para Empresas Multinacionales Andinas y su regulación especial ${ }^{23}$.

DREYZIN DE KLOR, Adriana; FERNÁNDEZ ARROYO, Diego (ed). Inversiones Extranjeras. Buenos Aires: Zavalia, 2005. p. 270. (DeCITA 03.2005).

19 Constitución de la República Bolivariana de Venezuela, publicada en Gaceta Oficial No. 5.453 Extraordinaria, de fecha 24/03/2000, texto disponible en $<$ http://www.ciemi.org.ve/pdf/ constitucion_venezuela.pdf $>$.

20 Artículo 112 de la Constitución de la República: “Todas las personas pueden dedicarse libremente a la actividad económica de su preferencia, sin más limitaciones que las previstas en esta Constitución y las que establezcan las leyes, por razones de desarrollo humano, seguridad, sanidad, protección del ambiente u otras de interés social. El Estado promoverá la iniciativa privada, garantizando la creación y justa distribución de la riqueza, así como la producción de bienes y servicios que satisfagan las necesidades de la población, la libertad de trabajo, empresa, comercio, industria, sin perjuicio de su facultad para dictar medidas para planificar, racionalizar y regular la economía e impulsar el desarrollo integral del país".

21 Artículo 301 de la Constitución de la República: "El Estado se reserva el uso de la política comercial para defender las actividades económicas de las empresas nacionales públicas y privadas. No se podrá otorgar a personas, empresas u organismos extranjeros regímenes más beneficiosos que los establecidos para los nacionales. La inversión extranjera está sujeta a las mismas condiciones que la inversión nacional".

22 Artículo 4 de la Ley de Promoción y Protección de Inversiones de 1999: "Las inversiones extranjeras directas, las inversiones subregionales, las inversiones de capital neutro y las inversiones de las Empresas Multinacionales Andinas en Venezuela continuarán sujetas a las Decisiones pertinentes de la Comunidad Andina de Naciones y a sus normas reglamentarias, incluidas las que se refieren al registro de tales inversiones. Esas inversiones disfrutarán también de la protección establecida por el presente Decreto-Ley y podrán disfrutar de los beneficios e incentivos que el mismo contempla, dentro de los límites que al efecto él establece”. 23 Véase el texto de las Decisiones 291 y 292 en <http://www.comunidadandina.org/ 
Era previsible tal eliminación vista la salida de la CAN por parte de la República, al denunciar el Acuerdo de Cartagena en el año 2006.

(ii) En segundo lugar, elimina todo el capítulo referido al tratamiento de la inversión extranjera en Venezuela contemplado en el instrumento legal derogado y contentivo del catálogo de garantías mínimas ofrecidas por la República a los inversionistas foráneos ${ }^{24}$. Normativa.aspx?GruDoc $=07>$ [consultado: $31 / 01 / 2015]$
24 Capítulo II, Tratamiento a la Inversión en Venezuela: "Articulo 6. Las inversiones
internacionales tendrán derecho a un trato justo y equitativo, conforme a las normas y criterios
del derecho internacional y no serán objeto de medidas arbitrarias o discriminatorias que
obstaculicen su mantenimiento, gestión, utilización, disfrute, ampliación, venta o liquidación.
Artículo 7. Las inversiones y los inversionistas internacionales tendrán los mismos derechos y
obligaciones a las que se sujetan las inversiones y los inversionistas nacionales en circunstancias
similares, con la sola excepción de lo previsto en las leyes especiales y las limitaciones
contenidas en el presente Decreto-Ley. Parágrafo Primero: Mediante Ley, podrán reservarse
determinados sectores de la actividad económica, al Estado o a inversionistas venezolanos.
Lo previsto en este Decreto-Ley no afecta las reservas existentes para la fecha de entrada en
vigencia de este Decreto-Ley.

Parágrafo Segundo: Las inversiones internacionales no requerirán de autorización previa para realizarse, excepto en los casos en que la ley expresamente así lo indique. Artículo 8. No se discriminará en el trato entre inversiones ni inversionistas internacionales, en razón del país de origen de sus capitales.

Parágrafo Único: Lo previsto en este artículo no será obstáculo para que puedan establecerse y mantenerse tratos más favorables en beneficio de inversiones e inversionistas de países con los que Venezuela mantenga acuerdos de integración económica, acuerdos para evitar la doble tributación o, en general, acuerdos relativos total o parcialmente a cuestiones impositivas.

Artículo 9. Las inversiones y los inversionistas internacionales, tendrán derecho al trato más favorable conforme a lo previsto en los artículos $7^{\circ}$ y $8^{\circ}$ de este Decreto-Ley.

Artículo 10. Las inversiones y los inversionistas venezolanos tendrán derecho a un trato no menos favorable que el otorgado a las inversiones internacionales, o a los inversionistas internacionales, según corresponda, en circunstancias similares.

Artículo 11. No se decretarán ni ejecutarán confiscaciones, sino en los casos de excepción previstos por la Constitución; y en cuanto a las inversiones e inversionistas internacionales, por el derecho internacional. Sólo se realizarán expropiaciones de inversiones, o se aplicarán a éstas medidas de efecto equivalente a una expropiación, por causa de utilidad pública o de interés social, siguiendo el procedimiento legalmente establecido a estos efectos, de manera no discriminatoria y mediante una indemnización pronta, justa y adecuada. La indemnización será equivalente al justo precio que la inversión expropiada tenga inmediatamente antes del momento en que la expropiación sea anunciada por los mecanismos legales o hecha del conocimiento público, lo que suceda antes. La indemnización, que incluirá el pago de intereses hasta el día efectivo del pago, calculados sobre la base de criterios comerciales usuales, se abonará sin demora.

Parágrafo Único: Las indemnizaciones a que haya lugar con motivo de expropiaciones de inversiones internacionales serán abonadas en moneda convertible y serán libremente transferibles al exterior.

Artículo 12. Las inversiones internacionales y en su caso, los inversionistas internacionales, tendrán derecho, previo cumplimiento de la normativa interna y al pago de los tributos a los que hubiere lugar a la transferencia de todos los pagos relacionados con las inversiones, tales como el capital inicial y las sumas adicionales necesarias para el mantenimiento, ampliación y desarrollo de la inversión; los beneficios, utilidades, rentas, intereses y dividendos; los fondos necesarios para el servicio y pagos de los créditos internacionales vinculados a una inversión; las regalías y otros pagos relativos al valor y la remuneración de los derechos de propiedad intelectual; las indemnizaciones a que se refiere el artículo $11^{\circ}$; el producto de la venta o liquidación total o parcial, de una inversión y los pagos resultantes de la solución de controversias. Las transferencias se efectuarán sin demora, en moneda convertible, al tipo de cambio vigente el día de la transferencia de conformidad con la reglamentaciones de cambio 
(iii) En tercer lugar, suprime la Superintendencia de Inversiones Extranjeras (SIEX), ente gubernamental que hasta los momentos estaba facultado para registrar y calificar las inversiones efectuadas en el país. Sus funciones las asume ahora el Centro Nacional de Comercio Exterior (CENCOEX).

(iv) En cuarto lugar, modifica el régimen de resolución de controversias. Ley.

De seguidas, revisamos los aspectos más resaltantes de la nueva

\subsection{Objetivo}

El instrumento legal tiene como propósito, de acuerdo al artículo 1,

... establecer los principios, políticas y procedimientos que regulan al inversionista y las inversiones extranjeras productivas de bienes y servicios en cualquiera de sus categorías, a los fines de alcanzar el desarrollo armónico y sustentable de la Nación, promoviendo un aporte productivo y diverso de origen extranjero que contribuya a desarrollar las potencialidades productivas existentes en el país, de conformidad con la Constitución (...) de la República Bolivariana de Venezuela, las leyes y el Plan de la Patria, a los fines de consolidar un marco que promueva,

en vigor para ese momento. Lo previsto en el presente artículo no será obstáculo para la aplicación de medidas, previstas en la ley, administrativas o judiciales para la protección de los derechos de los acreedores o en el curso de procesos que se ventilen ante los Tribunales de la República.

Parágrafo Primero: Podrán limitarse temporalmente las transferencias en forma equitativa y no discriminatoria, de conformidad con los criterios internacionalmente aceptados, cuando debido a una situación extraordinaria de carácter económico y financiero, la aplicación de lo previsto en este artículo resulte o pueda resultar en un grave trastorno de la balanza de pagos o de las reservas monetarias internacionales del país, que no sea posible solucionar adecuadamente mediante alguna medida alternativa. En estos casos, la medida que imponga la limitación deberá evitar todo daño innecesario a los intereses económicos, comerciales y financieros de las inversiones internacionales y de los inversionistas internacionales; y deberá ser liberada en la medida en que se corrija la situación extraordinaria que le hubiere dado origen y en consecuencia, disminuyan o se eliminen los graves trastornos de la balanza de pagos o de las reservas monetarias del país, o la amenaza de tales trastornos, según sea el caso. Parágrafo Segundo: En los casos de conversión de deuda externa en inversión, las remisiones quedarán sujetas a los plazos y condiciones establecidas en la normativa rectora de esa modalidad de inversión.

Artículo 13. Las administraciones estadales y municipales, dentro del ámbito de sus respectivas competencias, procurarán que sus impuestos, tasas y tributos a las actividades de industria y comercio no atenten contra las inversiones en términos de ser confiscatorios, ni obstaculicen el normal desarrollo de las mismas. Artículo 14. Con sujeción a las leyes, reglamentos y políticas relativas a la entrada y permanencia de extranjeros en el país, se permitirá el ingreso temporal al país a personas que le presten sus servicios a la empresa en la cual se ha realizado la inversión, o a su matriz, su filial o subsidiaria, empleadas en funciones administrativas o ejecutivas, $o$ involucradas en actividades que impliquen conocimientos especializados indispensables para el normal desenvolvimiento de la inversión, quedando a salvo las limitaciones establecidas en la legalización laboral". 
favorezca y otorgue previsible a la inversión" (subrayado nuestro).

La Ley califica o define qué se entiende por el término inversión o inversión extranjera, como veremos unas líneas más adelante, pero no califica qué se considera como "inversión extranjera productiva". Consideramos que su definición o concepto quedará a discreción de las autoridades competentes.

\section{2. Ámbito de aplicación personal}

Se consideran sujetos a la aplicación de la Ley, de acuerdo al artículo 4,

a) las empresas extranjeras y sus filiales, subsidiarias o vinculadas, regidas o no por Convenios y Tratados Internacionales; así como otras formas de organización extranjeras con fines económicos y productivos que realicen inversiones en el territorio nacional;

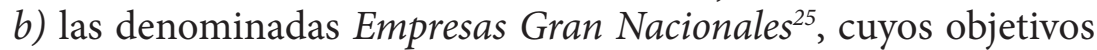
y funcionamiento están sujetos a un plan estratégico de dos o más Estados, que garanticen el protagonismo del poder popular ejecutando inversiones de interés mutuo a través de empresas públicas, mixtas, formas cooperativas y proyectos de administración conjunta;

c) las empresas nacionales (privadas, públicas y mixtas) y sus filiales, subsidiarias o vinculadas, regidas o no por Convenios y Tratados Internacionales y las demás organizaciones con fines económicos y productivos receptoras de Inversión Extranjera;

d) las personas naturales, nacionales o extranjeras, domiciliadas en el extranjero, que realicen inversiones extranjeras en el territorio nacional; $y$,

e) las personas naturales extranjeras residentes en el país que realicen inversiones extranjeras.

\subsection{Calificaciones}

La Ley deInversiones Extranjeras muestra un elenco de definiciones en su artículo 6. De seguidas revisamos las más importantes:

a) Inversión: corresponde a los recursos obtenidos lícitamente y destinados por un inversionista nacional o extranjero a la producción, de bienes y servicios que incorporen materias primas o productos intermedios con énfasis en aquellos de origen o fabricación nacional, en las proporciones y condiciones establecidas la Ley, que contribuyan a la

25 De acuerdo al artículo 6.10 de la Ley, una empresa gran nacional es una sociedad mercantil cuyo objetivo y funcionamiento están sujetos a un plan estratégico de dos o más Estados, en la ejecución de inversiones de interés mutuo a través de empresas públicas, mixtas, formas cooperativas y proyectos de administración conjunta. 
creación de empleos, promoción de la pequeña y mediana industria, y al desarrollo de innovación productiva.

b) Inversión Nacional: es aquella realizada por el Estado venezolano, las personas naturales o jurídicas nacionales y las realizadas por los ciudadanos extranjeros que obtengan la Credencial de Inversionista Nacional. Esta credencial la otorga el CENCOEX.

c) Inversión Extranjera: Es la inversión productiva efectuada a través de los aportes realizados por los inversionistas extranjeros conformados por recursos tangibles e intangibles, destinados a formar parte del patrimonio de los sujetos receptores de inversión extranjera en el territorio nacional.

Estos aportes pueden ser: (i) inversión financiera en divisas y/o cualquier otro medio de cambio o compensación instituido en el marco de la integración latinoamericana y caribeña; (ii) bienes de capital físicos o tangibles que formen parte del proceso productivo del sujeto receptor de la inversión; (iii) bienes inmateriales o intangibles constituidos por marcas comerciales, marcas de producto, patentes de invención, modelos de utilidad, diseños o dibujos industriales y derechos de autor, así como todos los derechos de propiedad industrial e intelectual consagrados en la Constitución y las Leyes.

Es importante destacar que la propia Ley indica que los aportes intangibles serán considerados como inversión extranjera cuando la cesión se realice entre empresas que no se encuentren directa o indirectamente vinculadas entre sí, previo registro del contrato de cesión ante el órgano nacional competente en materia de propiedad intelectual, denominado Servicio Autónomo de Propiedad Intelectual (SAPI); y, además, que la cesión de derechos involucre la transferencia efectiva al sujeto receptor de la inversión de la propiedad de los bienes cedidos; y, finalmente, (iv) reinversiones, constituida por las utilidades o dividendos no distribuidos de una inversión extranjera.

d) Inversionista Extranjero: La persona natural o jurídica extranjera que realice una inversión registrada ante el CENCOEX. La Ley expresamente indica que no califica como tal una persona natural o jurídica venezolana que, directamente o por interpuestas personas, figure como accionista de empresas extranjeras. Nos resulta contradictoria esta definición, toda vez que la Ley aplica para las personas naturales venezolanas con domicilio fuera de la República y que realizan inversiones extranjeras en el territorio nacional

e) Inversionista Nacional: Se considera inversionista nacional al Estado, a las personas naturales o jurídicas nacionales y al titular de la Credencial de Inversionista Nacional otorgada por el CENCOEX.

f) Empresa Nacional Receptora de Inversión Extranjera: Las sociedades mercantiles, cooperativas, empresas de propiedad social y otras formas de organización económica productiva definidas por la 
legislación nacional, cuyo capital social pertenezca mayoritariamente a inversionistas nacionales, en cincuenta y uno por ciento (51\%) o más, y sea calificada como tal por el CENCOEX.

g) Empresa Extranjera: Corresponde a las sociedades mercantiles cuyo capital social pertenezca en cincuenta y uno por ciento (51\%) o más a inversionistas extranjeros, y sea calificada como tal por el CENCOEX.

\subsection{Constitución y permanencia de la Inversión Extranjera}

Como regla general, los artículos 20 y 21 de la Ley de Inversiones Extranjeras indican que la inversión foránea puede establecerse en cualquier área de la economía conforme al orden jurídico local, a excepción de ciertos sectores reservados (como, por ejemplo, petróleo, gas, minería, banca y seguros) regulados por legislación especial y que permiten el aporte de capital extranjero bajo estándares distintos a la $\mathrm{Ley}^{26}$. De acuerdo a las nuevas disposiciones de este instrumento legal, el valor constitutivo de la inversión foránea debe representarse en activos, que se encuentren en el país, compuestos por equipos, insumos y otros bienes tangibles para el inicio de operaciones productivas en, al menos, $75 \%$ del monto total de la inversión.

A los fines de obtener el Registro de Inversión Extranjera ante las autoridades competentes (CENCOEX), se requiere que los aportes de la inversión sean por un monto mínimo equivalente a un millón de dólares de los Estados Unidos de América (USD 1.000.000,00) o su equivalente en otras divisas. Al tratarse de aportes en divisas libremente convertibles, el valor de la inversión se determinará conforme a la tasa de cambio oficial vigente al momento en que se hubiere efectuado la operación cambiaria y serán contabilizados con la presentación de los comprobantes emitidos por el CENCOEX. Debe también inscribirse en

26 A modo ilustrativo, citamos dos ejemplos: (i) el primero de ellos corresponde a la Ley Orgánica de Hidrocarburos (2006) que permite la constitución, bajo las condiciones que en cada caso especial se prevea, de empresas mixtas para el desarrollo de las actividades primarias (exploración, explotación, recolección, transporte y almacenamiento inicial de hidrocarburos) en las cuales la República detenta más del 50\% del capital social y permite la participación en menor proporción de inversión privada (local o extranjera). Para el caso de las denominadas actividades industriales (vale decir, separación, destilación, purificación; conversión, mezcla y transformación de hidrocarburos), pueden participar empresas mixtas con participación de capital estatal y privado, en cualquier proporción y también por empresas privadas. Y, para el supuesto de las actividades de comercialización, si se trata de productos distintos a hidrocarburos naturales o sus derivados, podrían participar empresas mixtas (con participación pública o privada) o empresas privadas. (ii) El segundo ejemplo lo constituye la nueva Ley de Instituciones del Sector Bancario (2014), promulgada también en el marco de la Ley Habilitante. Esta legislación impide que una persona jurídica constituida en un país de baja imposición fiscal sea accionista de una institución bancaria. Y, expresa que la participación de la inversión foránea en la actividad bancaria local puede efectuarse mediante (a) la adquisición de acciones en las instituciones existentes, (b) a través del establecimiento de bancos propiedad de inversores extranjeros, o (c) de sucursales de instituciones bancarias extranjeras. 
dicho registro las reinversiones y los aumentos de capital.

La inversión extranjera deberá permanecer en el territorio de la República, de acuerdo al artículo 29 de la Ley, por un lapso mínimo de cinco (5) años, contados a partir de la fecha en que haya sido otorgado el Registro. Una vez se cumpla este plazo, los inversionistas podrán, previo pago de los tributos y otros pasivos, realizar remesas al extranjero por concepto del capital originalmente invertido, registrado y actualizado.

De acuerdo a la Ley, toda inversión extranjera debe (i) contribuir con la producción de bienes y servicios nacionales, con el desarrollo económico nacional y la investigación e innovación en el país; (ii) establecer relaciones con Universidades e instituciones de investigación; (iii) implementar programas de responsabilidad social; (iv) canalizar los recursos a través del sistema financiero nacional; $(v)$ cumplir con los contratos de crédito externo e interno; $\mathrm{y},(v i)$ cumplir con la normativa local.

\subsection{Condiciones favorables a la Inversión}

El Ejecutivo Nacional puede establecer, conforme a los artículos 29 y 30 de la Ley, condiciones favorables, beneficios o incentivos particulares para la promoción y el estímulo de la Inversión extranjera. Consagra que el tratamiento a la inversión está sujeto a reglas de previsibilidad y seguridad jurídica, asegurando igualdad entre nacionales y extranjeros.

Vale destacar que estas previsiones también estaban contenidas en la derogada Ley de Promoción y Protección de Inversiones de 1999 y aún se mantienen las garantías contenidas en los Acuerdos Bilaterales de Promoción y Protección de Inversiones ratificados por la República. Sin embargo, tal como mencionamos al principio de este aparte, la nueva Ley eliminó todo el capítulo referido al tratamiento de la inversión extranjera tales como el Derecho al trato justo y equitativo conforme a las normas de Derecho Internacional; a la no discriminación en el trato entre inversiones ni inversionistas internacionales; al trato más favorable; a la no expropiación, salvo que se realice por causa pública o interés social con su correspondiente compensación); y, a la celebración de contratos de estabilidad jurídica, entre otras garantías ${ }^{27}$.

Es importante destacar que parte de dichas garantías y principios están contenidos en la Constitución Nacional cuyas disposiciones establecen el principio de libertad económica (artículo 112), el derecho a la propiedad, únicamente limitado en los casos de expropiaciones por causa pública o interés social, o en supuestos de confiscación por

27 HERNÁNDEZ-BRETON, Eugenio y ESIS VILLARROEL, Ivette. "Capítulo XXIII Venezuela”. En: BARONA VILAR, Silvia; ESPLUGUES MOTA, Carlos y ZAPATA DE ARBELÁEZ, Adriana (ed). El arbitraje interno e internacional en Latinoamérica: Regulación presente y tendencias de futuro. Bogotá: Universidad Externado de Colombia, 2010. p. 739-740. 
corrupción o por vinculación a actividades ilícitas (artículo 115) ${ }^{28}$; principio de no discriminación y trato favorable (artículo 301) ${ }^{29}$. Sin embargo, la exclusión en la nueva Ley del Capítulo del tratamiento a la inversión foránea constituye un retroceso a los pasos dados por la legislación de 1999 de brindar tratamiento legal y expreso a las garantías mínimas que la República se compromete a cumplir con los inversionistas extranjeros.

\subsection{Distribución, remesas, reinversión de utilidades o dividendos}

Las personas jurídicas, de acuerdo a los artículos 32 y siguientes de la Ley, pueden distribuir y pagar a sus inversionistas extranjeros en Venezuela y en moneda de curso legal, todo o parte de las utilidades netas al cierre de cada ejercicio económico. Éstos, a su vez, pueden remitir al exterior anualmente y a partir del cierre del primer ejercicio económico, hasta el ochenta por ciento $(80 \%)$ de las utilidades o dividendos comprobados que provengan de su inversión extranjera, registrada y actualizada en divisas libremente convertibles, previo cumplimiento del objeto de la inversión.

Los inversionistas extranjeros tienen también: (i) derecho a reinvertir total o parcialmente las utilidades obtenidas en moneda nacional, a los fines de ser consideradas como inversión extranjera, siempre que se notifique al CENCOEX y sea registrada esta modalidad ante dicho organismo; (ii) derecho a remesar al país de origen, total o parcialmente, los ingresos monetarios que obtengan producto de la venta dentro del territorio nacional de sus acciones o inversión, así como los montos provenientes de la reducción de capital, previo pago de los tributos correspondientes, cumplimiento del tiempo mínimo de permanencia de la inversión y los deberes establecidos por la normativa local. Es importante destacar que, en los supuestos de liquidación de la empresa, el Derecho a las remesas al exterior se limita hasta el ochenta y cinco por ciento (85\%) sobre el monto total de la inversión

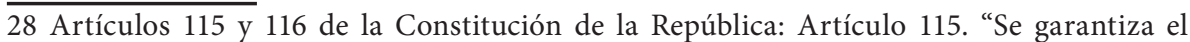
derecho de propiedad. Toda persona tiene derecho al uso, goce, disfrute y disposición de sus bienes. La propiedad estará sometida a las contribuciones, restricciones y obligaciones que establezca la ley con fines de utilidad pública o de interés general. Sólo por causa de utilidad pública o interés social, mediante sentencia firme y pago oportuno de justa indemnización, podrá ser declarada la expropiación de cualquier clase de bienes".

Artículo 116: "No se decretarán ni ejecutarán confiscaciones de bienes sino en los casos permitidos por esta Constitución. Por vía de excepción podrán ser objeto de confiscación, mediante sentencia firme, los bienes de personas naturales o jurídicas, nacionales o extranjeras, responsables de delitos cometidos contra el patrimonio público, los bienes de quienes se hayan enriquecido ilícitamente al amparo del Poder Público y los bienes provenientes de las actividades comerciales, financieras o cualesquiera otras vinculadas al tráfico ilícito de sustancias psicotrópicas y estupefacientes".

29 HERNÁNDEZ-BRETON, Eugenio y ESIS VILLARROEL, Ivette. Op. cit. p. 740. 
extranjera; y, (iii) para los casos de liquidación de la empresa receptora de la inversión foránea, el Derecho a transferir al país de origen de la inversión, siempre que tal liquidación sea producto de la venta de la empresa a inversionistas nacionales y se compruebe el funcionamiento de las operaciones por parte del CENCOEX.

\subsection{Registro de la Inversión Extranjera}

Los inversionistas deben contar con un registro de inversión extranjera, acreditado ante el CENCOEX. Este registro constituye un instrumento por el cual se acredita a la persona jurídica (la Ley no indica sobre las personas naturales), su condición como inversionista extranjero y le garantiza los beneficios de la Ley. Asimismo, las sociedades nacionales en su condición de receptoras de inversión extranjera, deben contar con un certificado de calificación de empresa, de manera que pueda ser acreditada como empresa nacional receptora, empresa extranjera o empresa gran nacional. Los requisitos no están contemplados en la legislación, pero se espera a la promulgación del Reglamento de la Ley para conocer los trámites a seguir.

Debe también registrarse y notificar al CENCOEX las actividades de las actividades desarrolladas con posterioridad al registro de la inversión foránea inicial, así como la reducción del capital social de las empresas receptoras de la inversión, de forma tal que el organismo emita una actualización de la calificación de la empresa y el registro de inversión extranjera.

\subsection{Autoridades Competentes}

El nuevo instrumento legal determina una serie de autoridades del Ejecutivo Nacional a los fines de garantizar el cumplimiento de la Ley. Así las cosas, corresponde al Ministerio con competencia en materia de comercio el dictamen de las políticas en materia de inversiones extranjeras; y, corresponde al Ministerio con competencia en materia de finanzas la facultad de sancionar a los sujetos que se encuentran bajo el ámbito de aplicación de la Ley ${ }^{30}$.

Se suprime la Superintendencia de Inversiones Extranjeras (SIEX) como órgano rector en la materia y, ahora, sus funciones (determinación de criterios, dictamen de normativa especial, procedimientos $\mathrm{y}$ registros) se atribuyen al CENCOEX, ente creado a finales de 2013 y que también ha absorbido, en el transcurso del tiempo, la competencia para

30 De acuerdo al artículo 47 de la Ley, las multas pueden oscilar entre 1000 y 100.000 Unidades Tributarias (UT). Cada Unidad Tributaria equivale a 150 Bolívares para la fecha de redacción de este trabajo. Estas multas, convertibles al tipo de cambio oficial vigente $(6,3 \mathrm{Bs} / \mathrm{USD})$ equivalen a más de 20.000 USD. 
instrumentar el régimen de control cambiario en el país ${ }^{31}$. En este orden de ideas, la propia Ley impone un lapso de 6 meses contados a partir de su publicación en Gaceta Oficial, para que el mencionado organismo dicte un Reglamento sobre las transferencias al exterior "... a los efectos de desarrollar el contenido en materia cambiaria” (Disposición Transitoria Segunda).

Junto al CENCOEX, se mantiene la competencia atribuida a varias autoridades (Ministerios y Superintendencias) relativas a los ámbitos de petróleo y minas, banca y seguros, tal como lo establecía la derogada Ley de 1999, quienes tienen la facultad de analizar, estudiar y emitir el Registro de Inversión Extranjera y sus actualizaciones, la emisión de la Constancia de Calificación de Empresas, el registro de contratos de transferencia tecnológica y efectuar las fiscalizaciones correspondientes. La nueva Ley establece un lapso de 6 meses para la adecuación de sus normas y procedimientos correspondiente de todas estas instancias.

Un aspecto que ha llamado la atención de la nueva Ley en su artículo 19 corresponde a las competencias adicionales que se atribuyen al Presidente del CENCOEX, dado que no sólo le corresponde ejercer la representación legal de dicho organismo, dirigir la administración interna del mismo y dictar las providencias a que haya lugar, sino que, además, puede emitir opinión sobre la suscripción o la denuncia de convenios y tratados internacionales en materia de inversión extranjera.

También se advierte respecto a la Disposición Transitoria Tercera de la Ley que exige que todo acuerdo marco de inversión o acuerdo comercial internacional en materia de inversión que suscriba y renegocie la República, debe fundamentarse en las disposiciones de la Ley. Podríamos considerar que esta previsión obedece al importante número de arbitrajes que ha enfrentado la República, durante los últimos años, ante los reclamos de inversionistas extranjeros ventilados

31 Publicada la Ley de su creación en Gaceta Oficial de la República Bolivariana de Venezuela $\mathrm{N}^{\circ} 6.116$ Extraordinario, de fecha viernes 29 de noviembre de 2013. El artículo 11 de la LIE indica las distintas funciones del CENCOEX: Colaborar con el Ejecutivo Nacional en la elaboración del Plan Anual de Promoción de Inversiones; Promover, fomentar y estimular las inversiones extranjeras y la transferencia tecnológica, en las áreas económicas y ámbitos territoriales de interés para el país en articulación con otros órganos del Ejecutivo Nacional; Autorizar y recomendar el direccionamiento de las inversiones extranjeras y la transferencia tecnológica, en las áreas económicas y ámbitos territoriales de interés para el país en articulación con otros órganos del Ejecutivo Nacional; Aprobar, rechazar, emitir, actualizar, renovar y revisar periódicamente la constancia de calificación de empresas, la credencial de inversionista nacional; el registro de las inversiones extranjeras y sus respectivas actualizaciones; los contratos de transferencia tecnológica; Sustanciar y decidir los procedimientos administrativos que dicten medidas preventivas; Fiscalizar las inversiones extranjeras y los contratos de transferencia tecnológica y asistencia técnica; Aprobar o negar la remisión de capitales, la solicitud de autorización de transferencia al extranjero de la propiedad sobre bienes de capital tangible e intangible, que se realice mediante operaciones financieras; Recaudar las tasas por los servicios prestados, procesamiento de documentos, las multas impuestas y demás derechos que le correspondan; Sustanciar procedimientos administrativos de carácter sancionatorio, entre otras. 
en el Centro Internacional de Arreglo de Diferencias entre Estados y Nacionales de otros Estados (CIADI). Sin embargo, pensamos también que todo acuerdo bilateral o multilateral que se suscriba en esta materia debe atender a las disposiciones constitucionales, tanto en el ámbito de la protección internacional de inversiones foráneas como en materia de integración regional ${ }^{32}$; $y$, a las mejores prácticas y condiciones que favorezcan a los Estados contratantes involucrados.

\subsection{Resolución de Controversias}

Se trata, sin duda, de una de las más resaltantes modificaciones de la Ley de Inversiones Extranjeras. La legislación derogada de 1999, contemplaba tres disposiciones en materia de resolución de controversias, mientras que la nueva sólo contempla un artículo al respecto.

\section{Ley derogada}

Artículo 21. Cualquier controversia que surja entre el Estado venezolano y el país de origen del inversionista internacional con el cual no se tenga vigente un tratado o acuerdo sobre inversiones, en relación con la interpretación y aplicación de lo previsto en el presente Decreto-Ley, será resuelta por vía diplomática. Si no se llegase a un acuerdo dentro de los doce (12) meses siguientes a la fecha de inicio de la controversia, el Estado venezolano propiciará el sometimiento de la controversia a un Tribunal Arbitral cuya composición, mecanismo de designación, procedimiento y régimen de gastos serán acordados por el otro Estado. Las decisiones de ese Tribunal Arbitral serán definitivas y obligatorias. Artículo 22. Las controversias que surjan entre un inversionista internacional, cuyo país de origen tenga vigente con Venezuela un tratado o acuerdo sobre promoción y protección de inversiones, o las controversias respecto de las cuales sean aplicables las disposiciones del Convenio Constitutivo del Organismo Multilateral de Garantía de Inversiones (OMGI-MIGA) o del Convenio sobre Arreglo de Diferencias Relativas a Inversiones entre Estados y Nacionales de Otros Estados (CIADI), serán sometidas al arbitraje internacional en

32 Artículo 153 de la Constitución de la República: "La República promoverá y favorecerá la integración latinoamericana y caribeña, en aras de avanzar hacia la creación de una comunidad de naciones, defendiendo los intereses económicos, sociales, culturales, políticos y ambientales de la región. La República podrá suscribir tratados internacionales que conjuguen y coordinen esfuerzos para promover el desarrollo común de nuestras naciones, y que garanticen el bienestar de los pueblos y la seguridad colectiva de sus habitantes. Para estos fines, la República podrá atribuir a organizaciones supranacionales, mediante tratados, el ejercicio de las competencias necesarias para llevar a cabo estos procesos de integración. Dentro de las políticas de integración y unión con Latinoamérica y el Caribe, la República privilegiará relaciones con Iberoamérica, procurando sea una política común de toda nuestra América Latina. Las normas que se adopten en el marco de los acuerdos de integración serán consideradas parte integrante del ordenamiento legal vigente y de aplicación directa y preferente a la legislación interna”. 
los términos del respectivo tratado o acuerdo, si así éste lo establece, sin perjuicio de la posibilidad de hacer uso, cuando proceda, de las vías contenciosas contempladas en la legislación venezolana vigente.

Artículo 23. Cualquier controversia que se suscite en relación con la aplicación del presente Decreto-Ley, una vez agotada la vía administrativa por el inversionista, podrá ser sometida a los Tribunales Nacionales o a los Tribunales Arbitrales venezolanos, a su elección.

\section{Ley vigente}

Artículo 5. Las inversiones extranjeras quedarán sometidas a la jurisdicción de los tribunales de la República, de conformidad con lo dispuesto en la Constitución de la República Bolivariana de Venezuela y demás leyes. La República Bolivariana de Venezuela podrá participar y hacer uso de otros mecanismos de solución de controversias construidos en el marco de la integración de América Latina y El Caribe.

Como podemos observar, la ley derogada contemplaba tres mecanismos:

a) El primero, artículo 21, relativo a las controversias suscitadas entre el Estado venezolano y el Estado de origen del inversionista con el cual la República no tenga vigente un tratado o acuerdo en materia de inversión. En este supuesto, la resolución del problema se tramitaba por vía diplomática. Si en el lapso de 6 meses no era resuelto, el Estado venezolano podía iniciar un proceso arbitral.

b) El segundo, artículo 22, relacionado con las disputas entre inversionistas foráneos y la República, contenía tres premisas: (i) si existía un acuerdo bilateral en materia de promoción y protección de inversiones entre la República y el Estado del cual el inversionista foráneo es nacional, el problema sería sometido a arbitraje conforme a la cláusula establecida en dicho convenio; (ii) si en la controversia aplicaba el OMGI-MIGA, ésta debía resolverse conforme a los términos de resolución de conflictos en él contenido; y, (iii) si además resultaba aplicable el Convenio de Washington sobre Arreglo de Diferencias relativas a Inversiones entre Estados y Nacionales de otros Estados, la disputa sería resuelta ante el CIADI.

La particular redacción de esta disposición permitía calificar al instrumento legal derogado como una categoría de legislaciones que, en materia de promoción y protección de inversiones, determinan en forma ambigua como medio de resolución de conflictos el arbitraje de inversión. Esto obedece a que si bien expresamente la disposición lo refiere, se requiere también de una nueva acción del Estado receptor para establecerlo, dado que el consentimiento estatal no es automático ${ }^{33}$. Su ambigüedad permitía dos interpretaciones potenciales: la primera,

33 DOLZER, Rudolf y SCHREUER, Christoph. Op. cit. p. 242. 
que sí establecía el consentimiento expreso del Estado venezolano de someterse al arbitraje de inversiones; y, la segunda: que sólo podría estar involucrado en un arbitraje de inversión si así lo establece el acuerdo multilateral o bilateral que la República haya ratificado ${ }^{34}$. Su redacción dejó lugar a muchas dudas, por lo que la doctrina advirtió sobre los riesgos de su interpretación ${ }^{35}$. La práctica arbitral, hasta los momentos, ha dado la razón a la segunda posición ${ }^{36}$.

c) El tercero, artículo 23, para el supuesto de no existencia de un acuerdo sobre promoción y protección de inversiones entre la República y el Estado del cual es nacional el inversionista, la controversia sería resuelta bien ante los tribunales nacionales o bien ante los tribunales arbitrales venezolanos.

La nueva Ley, como indicamos, derogó las tres disposiciones en materia de solución de controversias existentes y ahora dispone que las inversiones quedan sujetas a la jurisdicción de los tribunales venezolanos, de acuerdo a la Constitución y las leyes. Y, agrega que la República puede participar y utilizar otros mecanismos de resolución de controversias dispuestos en el marco de la integración latinoamericana y caribeña.

Podemos inferir de su redacción varias cuestiones:

a) Las controversias suscitadas entre el Estado venezolano y el Estado del cual es nacional el inversionista serán resueltas por vía diplomática y, de no llegar a un acuerdo, se someterán a los mecanismos contenidos en los Tratados suscritos y ratificados por ambos en la materia.

En el ámbito de MERCOSUR y, en particular, de acuerdo al Protocolo de Olivos, las diferencias suscitadas entre los Estados Partes sobre la interpretación, aplicación o cumplimiento de las normas del Tratado de Asunción y sus Acuerdos, el Protocolo de Ouro Preto, así como las Decisiones del Consejo del Mercado Común, las Resoluciones del Grupo Mercado Común y las Directivas de la Comisión de Comercio de MERCOSUR, se resolverán conforme a los mecanismos contenidos en dicho Protocolo ${ }^{37}$ :

(i) Negociación directa;

34 HERNÁNDEZ-BRETON, Eugenio y ESIS VILLARROEL, Ivette. Op. cit. p. 742.

35 DUGAN, Christopher; WALLACE, Don; RUBINS, Noah y SABAHI, Borzu. Investor-State Arbitration. New York: Oxford University Press, 2008. p. 232-233. Véase también SCHREUER, Christoph; MALINTOPPI, Loretta, REINISCH, August y SINCLAIR, Anthony. The ICSID Convention. A commentary. Cambridge: Cambridge University Press, 2010. p. 363.

36 Brandes Investment Partners, L.P. v. República Bolivariana de Venezuela, Caso No. ARB/08/03, Laudo sobre jurisdicción de fecha 02/08/2011. Texto disponible en: http://www. italaw.net [Consultado el 15/12/2014]; Cemex Caracas Investments B.V y Cemex Caracas II Investments, B.V. v. República Bolivariana de Venezuela, Caso No. ARB/08/15, Laudo sobre jurisdicción de fecha 30/12/2010. Texto disponible en: <http://icsid.worldbank.org/ICSID/ FrontServlet $>$ [consultado: 15/12/2014].

37 Veánse artículos 1, 4, 5 y siguientes del Protocolo de Olivos, texto disponible en: <http:// www.mercosur.int $>$ [consultado: 15/01/2015]. 
(ii) De no llegar a ningún acuerdo, el Estado reclamante puede optar entre iniciar un procedimiento arbitral ad hoc; o, de común acuerdo con el otro Estado, someterla a la consideración del Grupo Mercado Común.

(iii) Contra el laudo arbitral dictado en el mencionado procedimiento arbitral puede presentarse un recurso de revisión ante el Tribunal Permanente de Revisión (TPR), limitado a los asuntos de Derecho conocidos durante el litigio y a las interpretaciones jurídicas contenidas en el mencionado laudo.

(iv) Pueden las partes iniciar el procedimiento arbitral ad hoc ante el TPR en forma directa, supuesto en el cual los laudos dictados tienen el carácter de cosa juzgada, son obligatorios para los Estados Partes y no están sujetos a recurso de revisión.

b) Las disputas suscitadas entre Venezuela y un inversionista foráneo serán resueltas conforme a distintos mecanismos:

(i) De acuerdo a la cláusula de solución de controversias prevista en el convenio o acuerdo en materia de promoción y protección de inversiones entre Venezuela y el país de origen del inversionista;

(ii) Conforme a la cláusula de resolución de controversias que, en la materia, contenga la normativa en materia de integración latinoamericana o caribeña. En el ámbito de MERCOSUR y de acuerdo al Protocolo de Olivos, los particulares pueden efectuar reclamos derivados de la sanción o la aplicación de medidas discriminatorias, restrictivas o de competencia desleal por parte de un Estado Parte, en violación de la normativa del bloque regional, ante la Sección Nacional del Grupo Mercado Común del Estado Parte donde tengan su residencia habitual o sede de sus negocios ${ }^{38}$. Admitido el reclamo, la Sección debe efectuar consultas con la otra Sección Nacional del Estado Parte involucrado para llegar un acuerdo. De no obtenerlo, la Sección debe elevarlo al Grupo Mercado Común, quien a su vez admitirá el reclamo si considera que reúne los requisitos y convoca a un Grupo de Expertos. El Grupo de Expertos tomará una decisión respecto a la procedencia o no del reclamo. De considerarlo procedente, requerirá al Estado Parte el dictamen de las medidas correctivas o la anulación de las medidas acordadas contra el particular. De no considerarlo procedente, se da por concluido el procedimiento. Sin embargo, ello no obsta al Estado Parte reclamante a iniciar los mecanismos de resolución de controversias indicados en el literal $a$.

$38 \mathrm{Al}$ respecto, se considera que el Derecho al reclamo por parte de los particulares es bastante limitado, toda vez que no reconoce un verdadero ius standi a la persona natural o jurídica en los mecanismos de resolución de controversias mencionados. Véase al respecto, BOU FRANCH, Valentín. "La Solución de Controversias en el MERCOSUR". En: PIMENTEL, Luis Otávio; ESPLUGUES MOTA, Carlos y BARRAL, Welber (eds) Direito International Privado: União Européia e Mercosul. Florianópolis: Fundação Boiteux, 2007. p. 218. 
(iii) Para el supuesto en el cual no exista un convenio internacional en la materia entre Venezuela y el país de origen del inversionista, la disputa será resuelta ante los Tribunales venezolanos.

\section{CONCLUSIONES}

a) El régimen jurídico internacional de protección de inversiones extranjeras comprende un importante número de instrumentos convencionales de carácter multilateral y bilateral así como de legislaciones nacionales, cuyo propósito común consiste en fomentar las condiciones legales propicias para la inversión foránea en el mercado transfronterizo.

b) Los Estados tienen el derecho a determinar y controlar cómo se desarrollará la inversión extranjera en su territorio y, al mismo tiempo, les asiste el deber de ofrecer y mantener las garantías mínimas a los inversores foráneos y a las inversiones que admitan.

c) La nueva Ley de Inversiones Foráneas de Venezuela contiene una serie de requisitos para aceptar la inversión extranjera e impone una serie de obligaciones que deben cumplir los inversionistas (permanencia, cuantía y contribución al desarrollo socioeconómico del país). Sin embargo, derogó todo el capítulo referido al tratamiento de la inversión extranjera en Venezuela contemplado en la Ley de Promoción y Protección de Inversiones de 1999, contentivo del catálogo de garantías mínimas ofrecidas por la República a los inversionistas foráneos. Si bien el texto constitucional venezolano las enumera en forma genérica, esta eliminación constituye un retroceso a los pasos dados por la legislación anterior de ofrecer un instrumento legal expreso respecto al tratamiento de las mismas.

d) El CENCOEX es el nuevo órgano rector en materia de inversión extranjera, además de su competencia respecto al régimen cambiario desde el año 2013. Dicho ente tiene un lapso de 6 meses para dictar una serie de normas y resoluciones para instrumentar las nuevas reglas relativas a las transferencias de capital al exterior y los cambios a que refiere esta Ley.

e) Si bien la Ley de Inversiones Extranjeras dispone que todo nuevo acuerdo multilateral o bilateral que suscriba la República se debe fundamentar en sus disposiciones, la negociación de los tratados no puede atender únicamente a ello, sino también a la Constitución Nacional (en particular, las normas relativas protección internacional de inversiones foráneas como en materia de integración regional) $\mathrm{y}$, a las mejores prácticas y condiciones que favorezcan a los Estados involucrados.

f) Finalmente, la nueva Ley derogó las tres disposiciones que, en materia de solución de controversias, existían hasta la fecha. Los 
mecanismos de resolución de disputas contenidos en los tratados y acuerdos bilaterales de promoción y protección de inversiones ratificados por la República se mantienen. E igualmente, pueden utilizarse los mecanismos de los tratados de integración latinoamericana y caribeña, siempre que se cumplan los requisitos contenidos en ellos. Si no media ningún instrumento de carácter convencional entre las partes involucradas, el inversionista debe acudir ante los órganos jurisdiccionales venezolanos.

\section{REFERENCIAS BIBLIOGRÁFICAS}

BOU FRANCH, Valentín. "La Solución de Controversias en el MERCOSUR”. En: PIMENTEL, Luis Otávio; ESPLUGUES MOTA, Carlos y BARRAL, Welber (eds). Direito International Privado: União Européia e Mercosul. Florianópolis: Fundação Boiteux, 2007. p. 181-223. CASTILLO ARGAÑARÁS, Luís Fernando. "MERCOSUR e Inversiones Extranjeras. Una aproximación desde el Derecho Comparado y de la Integración”. En: Âmbito Jurídico [en línea]. 2011, vol 14 , n 84 [consultado el 25/01/2015]. Disponible en: <http://www.ambitojuridico.com.br/site?n_link_argios_leitura\&revista_cderno $=19>$.

DOLZER, Rudolf y SCHREUER, Christoph. Principles of International Investment Law. New York: Oxford University Press, 2008.

DUGAN, Christopher; WALLACE, Don; RUBINS, Noah y SABAHI, Borzu. Investor-State Arbitration. New York: Oxford University Press, 2008.

ESIS VILLARROEL, Ivette "Inversión Extranjera: Oportunidades y Desafíos para los países receptores”. En: VALENÇA FERRAZ, Carolina; SALOMÁO LEITE, Glauber; CECATO, Maria Áurea y NEWTON, Paulla da Costa (ed). Direito e Desenvolvimento Sustentável. São Paulo: Edit. Verbatim, 2013. p. 37-49.

FERNÁNDEZ MASIÁ, Enrique. Tribunales nacionales, arbitraje internacional y protección de las inversiones extranjeras. Madrid: Marcial Pons, 2008.

FERNÁNDEZ ROZAS, José Carlos. Tratado de Arbitraje Comercial en América Latina. Madrid: Iustel, 2008.

FRÍAS MILEO, María Lourdes. "Promoción y protección de la inversión en el MERCOSUR". En: Un Siglo de Historia y Derecho. 100 años del Escritorio Tinoco, Travieso, Planchart \& Núñez (TTP\&N). Caracas: TTP\&N y Universidad Católica Andrés Bello, 2014. p. 77-108.

HERNÁNDEZ-BRETON, Eugenio y ESIS VILLARROEL, Ivette. "Capítulo XXIII Venezuela". En: BARONA VILAR, Silvia; ESPLUGUES MOTA, Carlos y ZAPATA DE ARBELÁEZ, Adriana (ed). El arbitraje interno $e$ internacional en Latinoamérica: Regulación presente $y$ tendencias de futuro. Bogotá: Universidad Externado de Colombia, 2010. p. 719-748. 
HERNÁNDEZ-BRETÓN, Eugenio. "Protección de inversiones en Venezuela". En: DREYZIN DE KLOR, Adriana; FERNÁNDEZ ARROYO, Diego (ed). Inversiones Extranjeras. Buenos Aires: Zavalia, 2005. p. 270. (DeCITA 03.2005).

SCHREUER, Christoph; MALINTOPPI, Loretta, REINISCH, August y SINCLAIR, Anthony. The ICSID Convention. A commentary. Cambridge: Cambridge University Press, 2010.

UNCTAD. Towards a New Generation of International Investment Policies: UNCTAD's Fresh Approach to Multilateral Investment PolicyMaking [en línea]. [consultado: 25/01/2015]. Disponible en: <http:// unctad.org/en/PublicationsLibrary/webdiaepcb2013d6_en.pdf $>$.

VENEZUELA. Ley Aprobatoria del Protocolo de Adhesión de la República Bolivariana de Venezuela al MERCOSUR y sus Anexos: "Tratado de Asunción", "Protocolo de Ouro Petro", "Protocolo de Olivos para la Solución de Controversias del MERCOSUR" y la "Lista de Productos paraguayos y uruguayos que, conforme al artículo 5 del Protocolo, gozarán de desgravación total e inmediata por parte de la República Bolivariana de Venezuela. Gaceta Oficial de la República Bolivariana de Venezuela No. 38.482, de 19/07/2006.

VENEZUELA. Constitución de la República Bolivariana de Venezuela. Gaceta Oficial No. 5.453 Extraordinaria, de 24/03/2000.

VENEZUELA. Ley de Inversiones Extranjeras. Gaceta Oficial de la República Bolivariana de Venezuela No. 6.152 Ext., de 18/11/2014.

VENEZUELA. Ley de Promoción y Protección de Inversiones. Gaceta Oficial de la República Bolivariana de Venezuela No. 5.390 Ext., de 22/10/1999.

VENEZUELA. Ley que autoriza al Presidente de la República para dictar Decretos con Rango, Valor y Fuerza de Ley en las materias que se delegan. Gaceta Oficial de la República Bolivariana de Venezuela No. 6.112 Ext., de 19/11/2013. 